\title{
Ursolic acid induces cell cycle arrest and apoptosis of gallbladder carcinoma cells
}

\author{
Hao Weng ${ }^{1,2,3 \dagger}$, Zhu-Jun Tan ${ }^{1,2,3+}$, Yun-Ping Hu ${ }^{1,2,3}$, Yi-Jun Shu ${ }^{1,2,3}$, Run-Fa Bao ${ }^{1,2,3}$, Lin Jiang ${ }^{1,2,3}$, Xiang-Song Wu ${ }^{1,2,3}$, \\ Mao-Lan Li ${ }^{1,2,3}$, Qian Ding ${ }^{1,2,3}$, Xu-an Wang ${ }^{1,2,3}$, Shan-shan Xiang ${ }^{1,2,3}$, Huai-Feng $\mathrm{Li}^{1,2,3}$, Yang Cao ${ }^{1,2,3}$, Feng Tao ${ }^{4^{*}}$ \\ and Ying-Bin $\mathrm{Liu}^{1,2,3^{*}}$
}

\begin{abstract}
Background: Ursolic acid (UA), a plant extract used in traditional Chinese medicine, exhibits potential anticancer effects in various human cancer cell lines in vitro. In the present study, we evaluated the anti-tumoral properties of UA against gallbladder carcinoma and investigated the potential mechanisms responsible for its effects on proliferation, cell cycle arrest and apoptosis in vitro.

Methods: The anti-tumor activity of UA against GBC-SD and SGC-996 cells was assessed using MTT and colony formation assays. An annexin V/PI double-staining assay was used to detect cell apoptosis. Cell cycle changes were detected using flow cytometry. Rhodamine 123 staining was used to assess the mitochondrial membrane potential $(\Delta \psi \mathrm{m})$ and validate UA's ability to induce apoptosis in both cell lines. The effectiveness of UA in gallbladder cancer was further verified in vivo by establishing a xenograft GBC model in nude mice. Finally, the expression levels of cell cycle- and apoptosis-related proteins were analyzed by western blotting.
\end{abstract}

Results: Our results suggest that UA can significantly inhibit the growth of gallbladder cancer cells. MTT and colony formation assays indicated dose-dependent decreases in cell proliferation. S-phase arrest was observed in both cell lines after treatment with UA. Annexin V/PI staining suggested that UA induced both early and late phases of apoptosis. UA also decreased $\Delta \psi \mathrm{m}$ and altered the expression of molecules regulating the cell cycle and apoptosis. In vivo study showed intraperitoneally injection of UA can significantly inhibited the growth of xenograft tumor in nude mice and the inhibition efficiency is dose related. Activation of caspase-3,-9 and PARP indicated that mitochondrial pathways may be involved in UA-induced apoptosis.

Conclusions: Taken together, these results suggest that UA exhibits significant anti-tumor effects by suppressing cell proliferation, promoting apoptosis and inducing 7cell cycle arrest both in vitro and in vivo. It may be a potential agent for treating gallbladder cancer.

Keywords: Ursolic acid, Gallbladder cancer, Proliferation, Cell cycle, Apoptosis, Mitochondrial-mediated pathway

\footnotetext{
*Correspondence: tf_zjsx@aliyun.com; liuybphd@126.com

${ }^{\dagger}$ Equal contributors

${ }^{4}$ Gastrointestinal Surgery, Shaoxing People's Hospital Shaoxing Hospital of

Zhejiang University, No. 568 Zhongxing North Road, Shaoxing 312000,

Zhejiang Province, China

'Department of General Surgery, Xinhua Hospital, Affiliated to Shanghai Jiao

Tong University, School of Medicine, Shanghai, China

Full list of author information is available at the end of the article
} 


\section{Background}

Gallbladder cancer (GBC) is the most common malignancy of the biliary tract and the 5th most common digestive tract cancer [1]. Owing to a lack of specific signs and symptoms, many patients are not diagnosed until the cancer has reached an advanced stage, with local invasion and distant metastasis. As a result, GBC patients have poor prognoses, and the 5-year survival rate is approximately $5 \%$ [2]. Surgical resection is the only potentially effective treatment for $\mathrm{GBC}$, but recurrence rates remain high, even after radical resection [3]. In addition, GBC is resistant to chemotherapy or radiotherapy, hindering the prevention of tumor development and recurrence. Novel and more effective chemotherapeutic agents are urgently needed to treat GBC. Ursolic acid (UA) (Figure 1A) is a pentacyclic triterpene acid that can be extracted from a number of plants, including fruits and medicinal herbs, and has a variety of clinical applications. In addition to its antioxidant, anti-hepatitis, anti-inflammatory and hypolipidemic effects, the most remarkable property of UA is its anti-tumor activity. UA inhibits cell growth and induces apoptosis in several cancers, including colon cancer, breast cancer, leukemia, melanoma and prostate cancer [4-8]. This cell growth inhibition is mediated by BAX through the suppression of the PI3K/Akt pathway. UA downregulates the expression of STAT3-regulated gene products such as cyclin D1, Bcl-2, Bcl-xL, survivin, Mcl-1 and VEGF in multiple
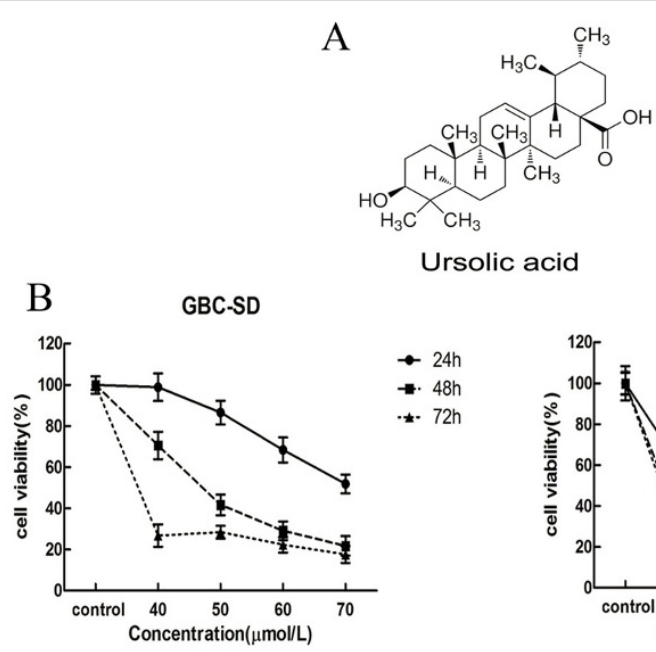

$\mathrm{B}$
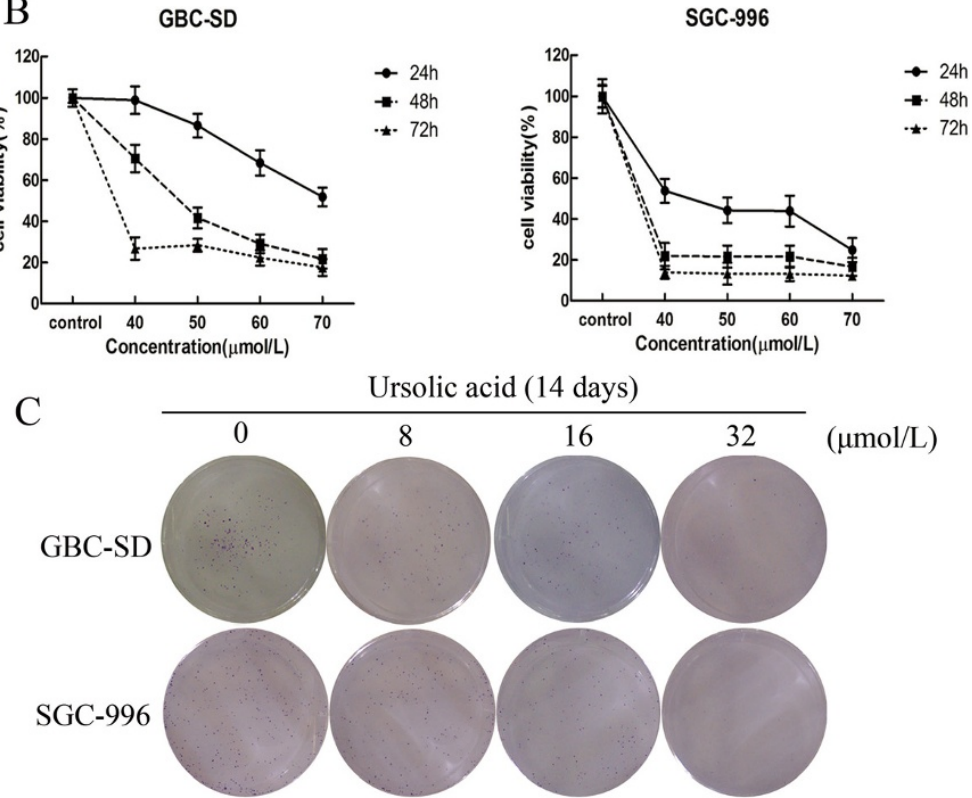

$\mathrm{D}$
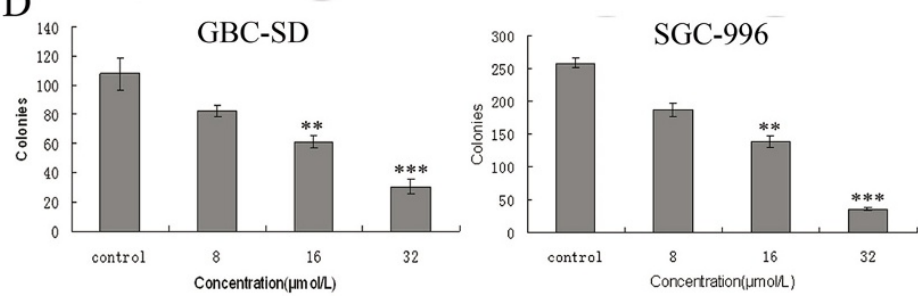

Figure 1 UA inhibits proliferation in GBC cells. (A) The chemical structure of UA. (B) GBC-SD and SGC-996 cells were treated with various concentrations of UA for 24,48 or $72 \mathrm{~h}$. Effects on cell proliferation were determined using a MTT assay. Each value represents the mean \pm SD $(n=3)$. (C-D) UA inhibits colony formation in GBC cells. GBC-SD and SGC-996 cells were treated with different doses of UA ( 8 , 16 or $32 \mu \mathrm{mol} / \mathrm{L})$ and were allowed to form colonies in fresh medium for 14 days. The photomicrographic differences and number of colonies (mean \pm SD, $n=3$ ) in colony formation are shown. Significant differences from the control are indicated by ${ }^{*} p<0.05$ and ${ }^{* *} p<0.01$. 
myeloma cells [9]. Other studies have suggested that UA induces apoptosis through caspase-3 activation concomitant with a significant decrease in Bcl-2 and survivin expression [10]. UA also inhibits JNK expression and IL-2 activation in Jurkat leukemic T cells, resulting in reduced proliferation and $\mathrm{T}$ cell activation [11]. Despite considerable research on the effects of UA on various cancers, no detailed studies have investigated the effects of UA on human gallbladder carcinoma. In the present study, we confirm the anti-neoplastic activity of UA in GBC cell lines (including GBC-SD and SGC-996) and provide insight into the molecular mechanisms underlying this activity. Its tumor growth inhibition effectiveness was further verified by in vivo study.

\section{Results}

\section{Effects of UA on the viability of gallbladder carcinoma} cell lines

According to the MTT assay results shown in Figure 1B, the proliferation of both GBC-SD and SGC-996 cells was inhibited after treatment with different concentrations of UA for different periods. Furthermore, inhibition was dose- and time-dependent. The groups at $48 \mathrm{~h}$ were chosen to detect changes in molecular events during the subsequent experiments. The IC50 values in GBC-SD and SGC-996 cells at $48 \mathrm{~h}$ were approximately $47.6 \mu \mathrm{mol} / \mathrm{L}$ and $28.5 \mu \mathrm{mol} / \mathrm{L}$, respectively.

\section{Effects of UA on colony formation by gallbladder carcinoma cell lines}

The ability of GBC-SD and SGC-996 cells to form colonies in the presence of UA was analyzed using a flat plate colony formation assay. The results shown in Figure $1 \mathrm{C}$ suggest that UA effectively inhibited colony formation in both cell lines in a dose-dependent manner. Moreover, statistical analysis demonstrated that the mean sizes of the control colonies were larger than the colonies of the drug-treated groups (Figure 1D). This finding suggests that UA may significantly affect GBC-SD and SGC-996 cell proliferation.

\section{UA-induced cell cycle arrest and apoptosis in gallbladder carcinoma cell lines}

Flow cytometry was used to determine the effects of UA on cell cycle distribution and apoptosis; the results are shown in Figure 2. After treatment with UA for $48 \mathrm{~h}$, the percentage of S-phase cells in GBC-SD colonies was significantly higher than in the control group $(36.84 \%$ and $51.12 \%$ in the $50 \mu \mathrm{mol} / \mathrm{L}$ and $60 \mu \mathrm{mol} / \mathrm{L}$ groups, respectively, versus $26.72 \%$ in the control group). In addition, the percentage of S-phase cells in the SGC-996 cell line was $16.38 \%$ in the control group, $21.40 \%$ in the $40 \mu \mathrm{mol} / \mathrm{L}$ group, $30.52 \%$ in the $50 \mu \mathrm{mol} / \mathrm{L}$ group and $41.63 \%$ in the $70 \mu \mathrm{mol} / \mathrm{L}$ group. Both cell lines achieved peak apoptosis once they were treated with $>50 \mu \mathrm{mol} / \mathrm{L}$ UA. These results suggest that UA arrests the cell cycle at the $S$ phase and induces apoptosis in vitro.

\section{Flow cytometric estimation of UA-induced apoptosis}

Phosphatidylserine (PS) is located inside normal cells and is transferred to the surface during the early stage of cell apoptosis. Annexin V, a $\mathrm{Ca}^{2+}$-dependent phospholipid binding protein, has a strong binding affinity for PS. Thus, we used an annexin V-FITC/PI staining kit to assess UA-induced cell apoptosis. The results shown in Figure 3 indicate a remarkable dose-dependent increase in both the early and late stages of apoptosis in both cell lines compared with the control group.

\section{Effects of UA on $\Delta \Psi_{\mathrm{m}}$}

To validate the ability of UA to induce apoptosis in GBC-SD and SGC-996 cells, we performed a cellular functional assay. Rhodamine 123 staining was used to detect the integrity of the mitochondrial membrane. Loss of $\Delta \Psi \mathrm{m}$ was correlated with a decrease in the intensity of fluorescent staining. As shown in Figure 4, after UA treatment, the ratio of Rhodamine 123-negative cells increased from $3.56 \%$ to $63.3 \%$ in GBC-SD cells and from $5.63 \%$ to $98.8 \%$ in SGC-996 cells. This increase occurred in a dosedependent manner, suggesting that UA induces cancer cell apoptosis through a mitochondria-dependent mechanism.

\section{Effects of UA on the signal pathway of caspase and Bcl-2 family members}

To investigate the molecular mechanism underlying the apoptotic effects of UA on gallbladder carcinoma cells, we assessed the expression of several apoptosis-related proteins, including PARP, caspase-3, caspase-9, cytochrome c, Bax and Bcl-2, by western blot analysis. As shown in Figure 5, as the concentration of UA increased, Bax protein expression increased, while Bcl-2 expression decreased. The Bax/Bcl-2 ratio increased in both cell lines, suggesting that these proteins are involved in UA-induced apoptosis. In the caspase pathway, cleaved caspase-3, -9 and PARP levels were upregulated after treatment with UA in a dose-dependent manner. Caspase-3 is a major functional enzyme in the cellular apoptotic signaling pathway, which suggests that UA may induce $\mathrm{GBC}$ cell apoptosis via caspase-3 activation.

\section{UA suppresses tumor growth in vivo}

We successfully established GBC xenograft model in 45 nude mice. To evaluate the anti-tumor effect of UA, mice in 3 groups were administered UA or vehicle solvent for 21 days.The tumors removed from these mice are shown in Figure 6A, B, and their mean weights were provided in Figure 6C. Compare to the control group, the tumor volume and weight in UA treated group was 


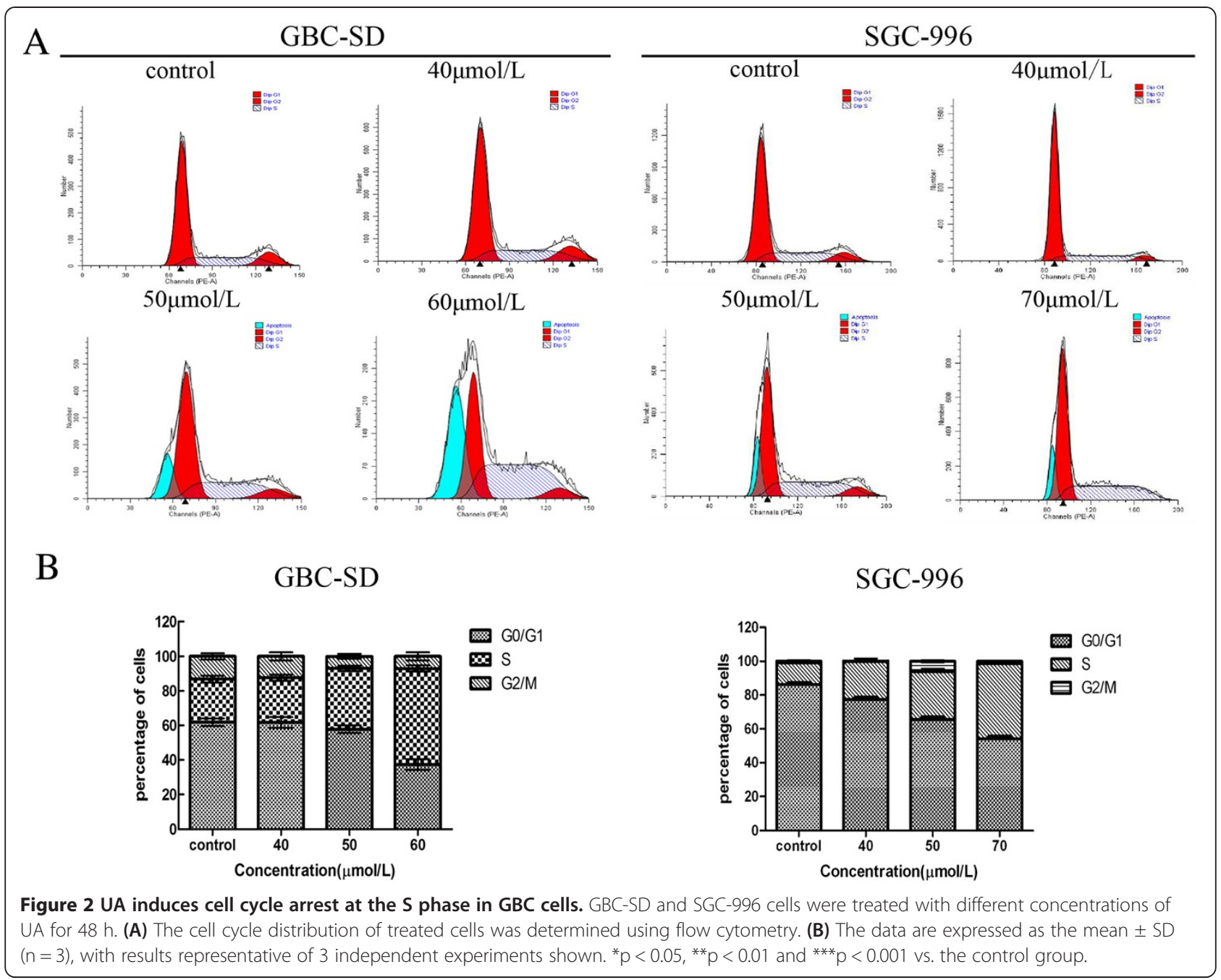

significantly reduced, and the reduction is dose related. These results accord with our in vitro study and further confirmed the effectiveness of UA in gallbladder cancer.

\section{Discussion}

Most malignant tumors remain incurable and are associated with a poor prognosis. Traditional Chinese medicine (TCM) treats cancer in a unique way compared to Western medicine. For example, in TCM, the body as a whole is emphasized, and treatment is focused on modulating the body's internal environment, including "Blood Qi" flow and "Yin-Yang" balance [12]. These concepts do not exist in Western medicine, and thus, therapeutic effects related to these ideas are not widely accepted.

Recently, the molecular anti-tumor mechanisms of a large catalogue of traditional Chinese drugs were investigated, revealing that these drugs have the same antitumor properties as drugs used in Western medicine, expanding our understanding of TCM and chemotherapy [13-16].
The process of tumor development requires multiple steps, including cell initiation, proliferation, invasion and metastasis $[17,18]$. We have previously identified several other medicines that inhibit tumor cell proliferation and induce apoptosis, thereby influencing the process of tumor development $[17,19]$. In the present study, we investigated the anti-tumoral properties of UA. The results of cytology and proteomics experiments allow us to conclude for the first time that UA has anticancer properties in GBC cells similar to those previously observed for other cancer cell types.

The drug's cytotoxicity was evaluated using MTT and colony formation assays. The MTT assay results indicated that at concentrations $>40 \mu \mathrm{mol} / \mathrm{L}$, UA significantly inhibited GBC-SD and SGC-996 cell growth in a time- and dose-dependent manner. The SGC-996 cells were more sensitive, and an exposure time of $48 \mathrm{~h}$ was determined to be the most suitable for subsequent experiments. In the colony formation assays, a smaller dose of UA (>16 $\mu \mathrm{mol} / \mathrm{L}$ ) effectively inhibited colony formation in 


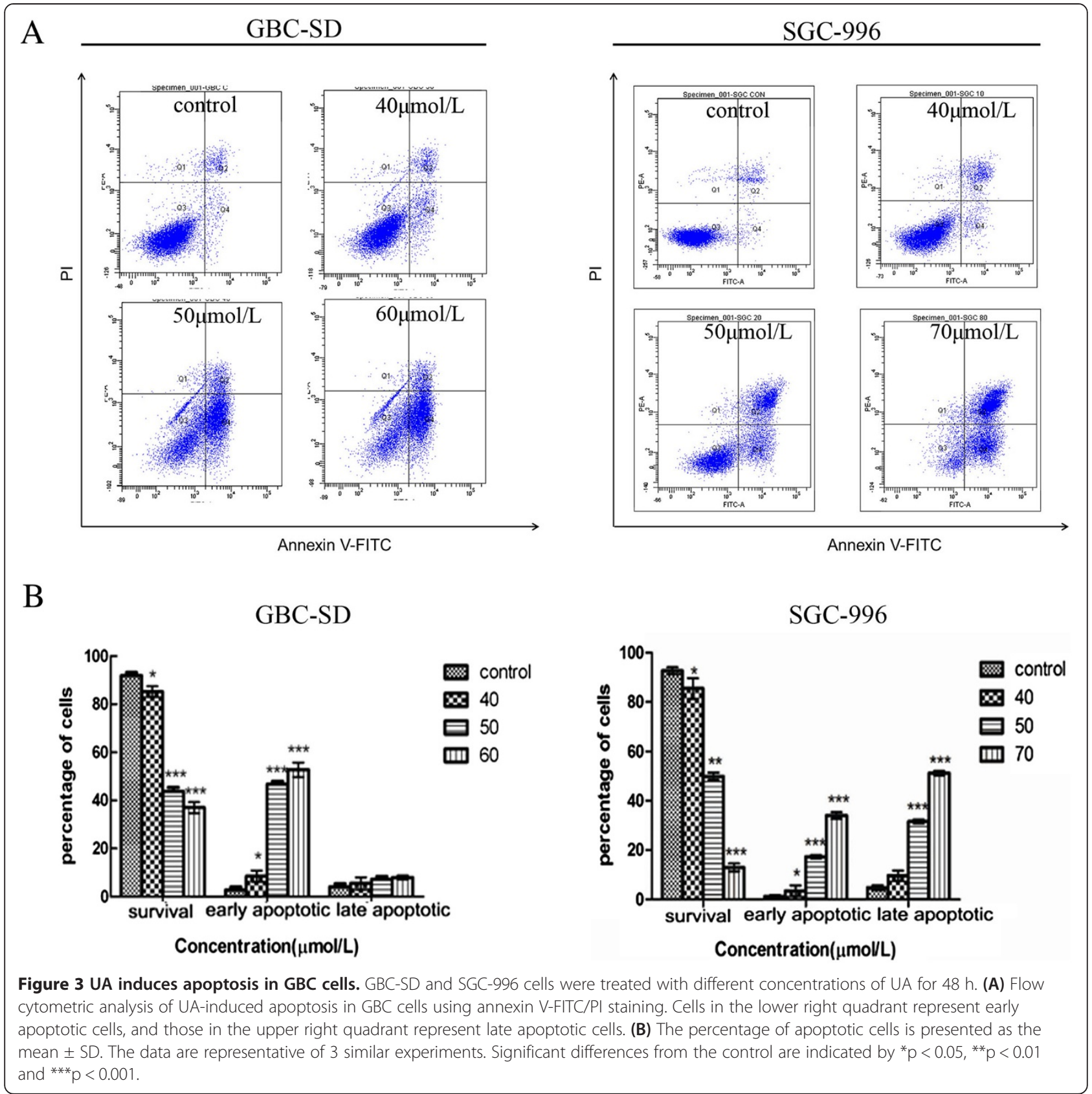

both cell lines. Taken together, these results indicate that UA suppresses cancer cell growth. To better understand the effect of UA, flow cytometric analysis was performed. The results of this analysis suggested that UA causes S-phase arrest in a dose-dependent manner. Cell cycle arrest may be the mechanism by which UA inhibits the proliferation of cancer cells.

Apoptosis is an area of intense interest in cancer research. The process of programmed cell death involves a cascade of molecular events that are initiated by several stimuli [20]. After confirming the apoptosis-inducing effects of UA by flow cytometry, we examined the variation in $\Delta \Psi \mathrm{m}$, as mitochondria play an important role in regulating many cellular functions. During the early stage of cell apoptosis, the permeability of the mitochondrial membrane is increased, consequently decreasing $\Delta \Psi \mathrm{m}$. Our study suggests that UA-induced apoptosis is closely related to this decrease in $\Delta \Psi \mathrm{m}$.

The mitochondrial pathway is one of the three major pathways involved in apoptosis, and NF- $\mathrm{KB}$ is a critical transcription factor that regulates the transcription of many genes associated with tumorigenesis [21]. Its target gene, $\mathrm{Bcl}-2$, is also a central regulator of this process. Bcl-2 family proteins play key roles in controlling the 


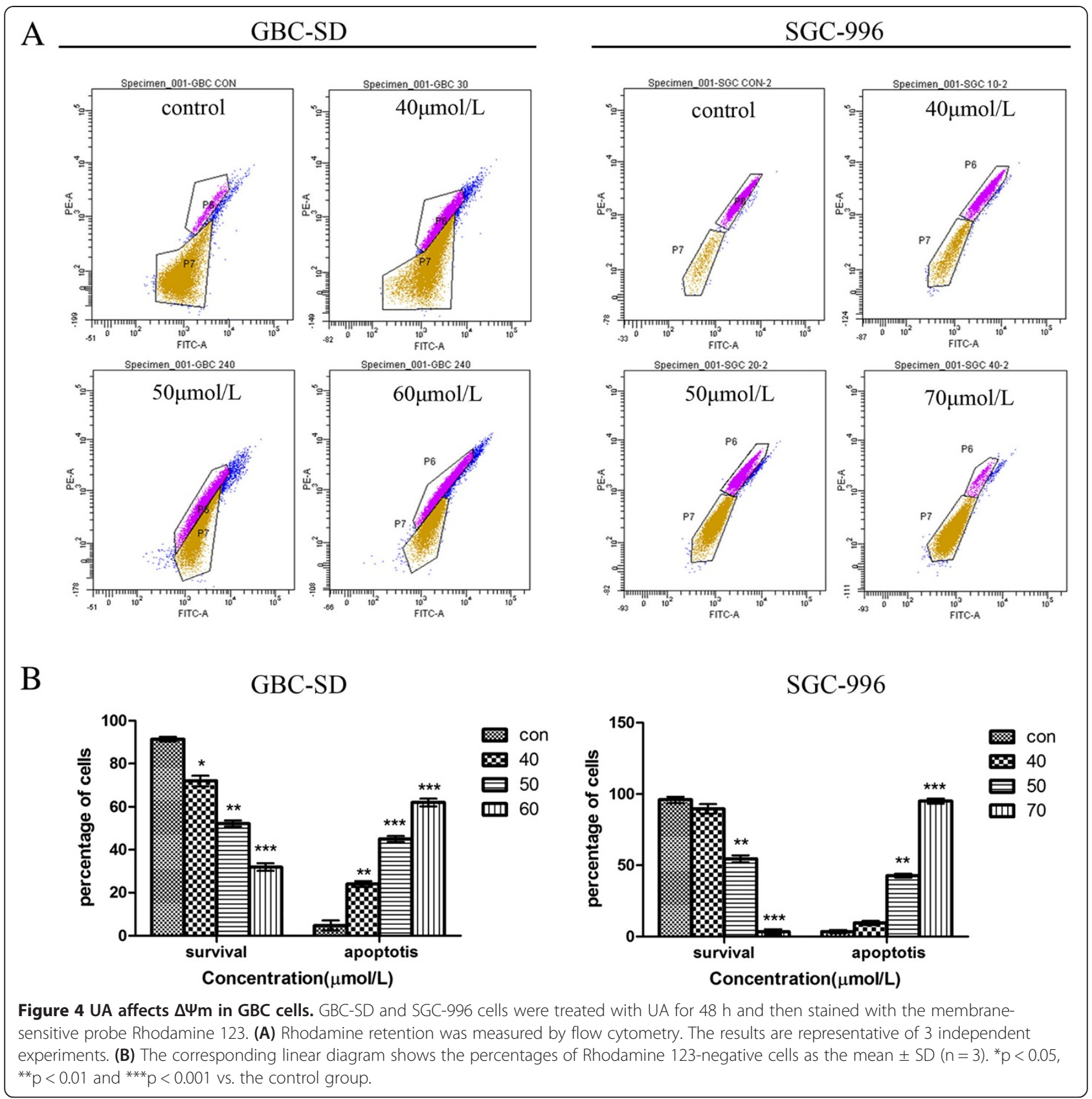

mitochondrial pathway [22,23]. The Bcl-2 family is divided mainly into $\mathrm{Bax}, \mathrm{Bcl}-2$ and Bid proteins based on their different biological effects. Bcl-2 is regarded as a key apoptosis inhibitor which binds to the mitochondrion and prevent the release of cytochrome $\mathrm{c}$ from the mitochondria. On the other hand, Bax acts as an apoptosis promoter via increase the permeability of the mitochondria, which leads to membrane potential loss and cytochrome c releasing. The destiny of a cell is determined by the ratio of these two proteins, $\mathrm{Bcl}-2 / \mathrm{Bax}$. In the present study, the Bcl-2/Bax ratio was decreased by treatment with UA, causing the elevation level of cytochrome $\mathrm{c}$ in the cytosol. Which suggests that UA suppresses NF-kB nuclear localization and changes the proportion of proapoptotic and anti-apoptosis proteins in Bcl-s family to induce tumor cell apoptosis.

As the Bcl-2/Bax ratio decreases, it can also cause caspase activation and PARP cleavage.Caspase- 9 is activated in the mitochondria-mediated intrinsic pathway. It can subsequently activate Caspase-3. Caspase- 3 is known as the "executor of apoptosis". It can mediates apoptosis in many human cells and in many ways, such as by degrading anti-apoptosis proteins and cleaving DNA repair molecules, extracellular matrix proteins, skeleton proteins and 


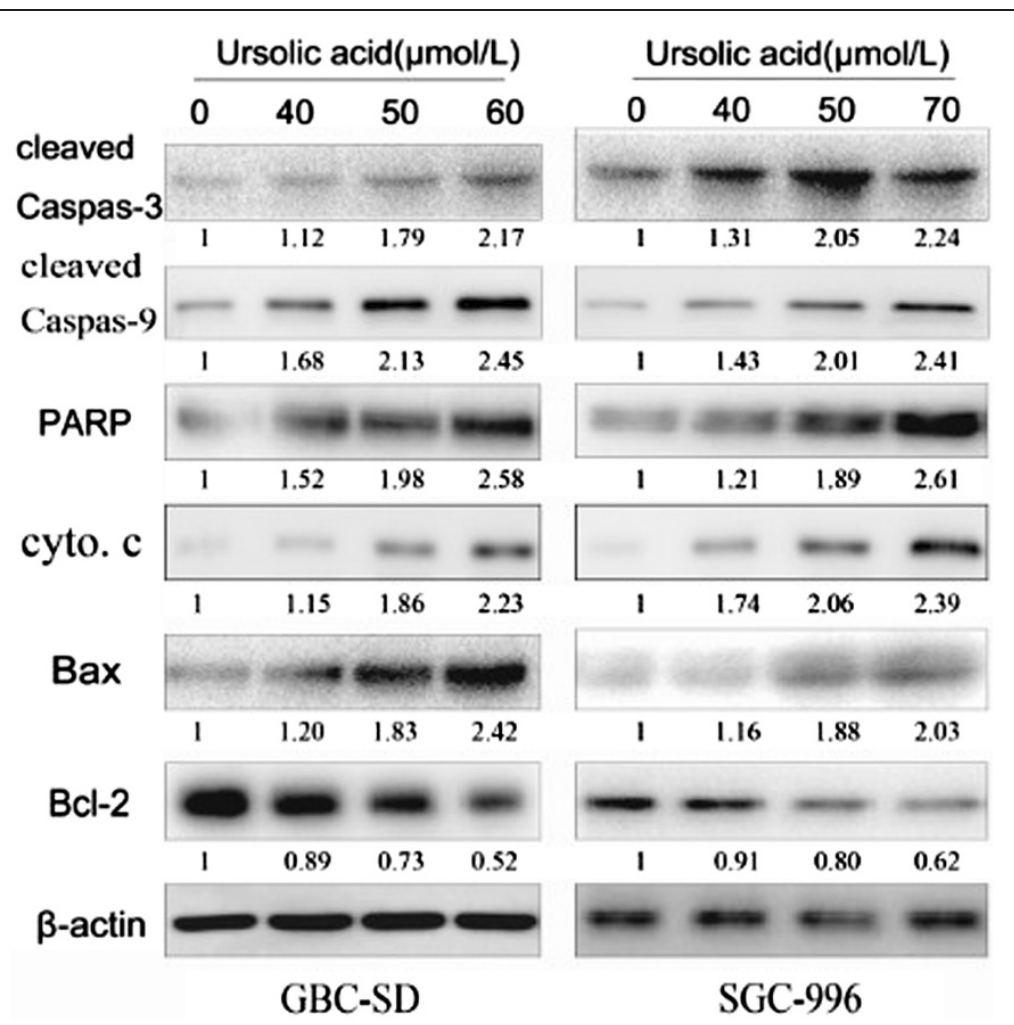

Figure 5 UA modulates the expression of cell cycle- and apoptosis-related proteins in GBC cells. Western blot analysis of protein extracts from GBC-SD and SGC-996 cells treated with different doses of UA for 48 h. The expression levels of cleaved caspase-3, caspase-9, PARP, cyto c, Bax and BCl-2 were analyzed. $\beta$-Actin was used as a loading control. The results are representative of 3 independent experiments.

other related molecules [24]. Once activated, caspase-3 can systematically dismantle cells by cleaving key proteins such as PARP. The changes in cleaved caspase-3 and -9 expression observed in our study were consistent with the changes in cell apoptosis observed after treatment with UA. PARP cleavage increased accordingly, suggesting the involvement of a caspase-dependent pathway via caspase3 in UA-induced apoptosis.

\section{Conclusion}

In summary, our results indicate that UA exhibits potent anti-GBC properties by suppressing cell proliferation, promoting apoptosis and inducing cell cycle arrest in vitro. It can also suppresses tumor growth in vivo. Activation of the mitochondrial-mediated apoptosis pathway is one possible mechanism responsible for these effects. Our work provides a new perspective on the function of UA in tumor chemotherapy, and we believe that further exploration of similar TCM drugs will reveal additional chemotherapeutic mechanisms.

\section{Methods}

Drugs and antibodies

UA was purchased from Sigma-Aldrich (St Louis, MO, USA) in the purity of $99.56 \%$ and dissolved in dimethyl sulfoxide (DMSO). The stock solution was stored at $-20^{\circ} \mathrm{C}$. Before use, the drug was defrosted and diluted with cell culture medium to different concentrations. The following antibodies were used: rabbit reactive monoclonal anticleaved caspase-3, anti-PARP, anti-Bcl-2 and anti-Bax antibodies and a mouse anti- $\beta$-actin antibody. All antibodies were obtained from Cell Signaling Technology (Danvers, MA, USA).

\section{Cell lines and culture}

The human cell lines GBC-SD and SGC-996 were purchased from the Shanghai Cell Institute Country Cell Bank. GBC-SD cells were cultured in high-glucose DMEM (Gibco, USA) at $37^{\circ} \mathrm{C}$ in a $5 \% \mathrm{CO}_{2}$ incubator, while SGC996 cells were cultured in Roswell Park Memorial Institute (RPMI) 1640 medium. Both types of culture medium were supplemented with $10 \%$ fetal bovine serum (Gibco, USA), penicillin $(100 \mathrm{U} / \mathrm{mL})$ and streptomycin $(100 \mathrm{U} / \mathrm{mL})$ (Utah, HyClone, USA).

\section{UA cytotoxicity assay}

A drug cytotoxicity assay was performed using the MTT method. In brief, GBC-SD and SGC-996 cells were placed in 96-well culture plates at a density of $5 \times 10^{3}$ cells per well. After culturing overnight, the initial culture medium 


\section{Ursolic acid (mg/kg 21 days)}
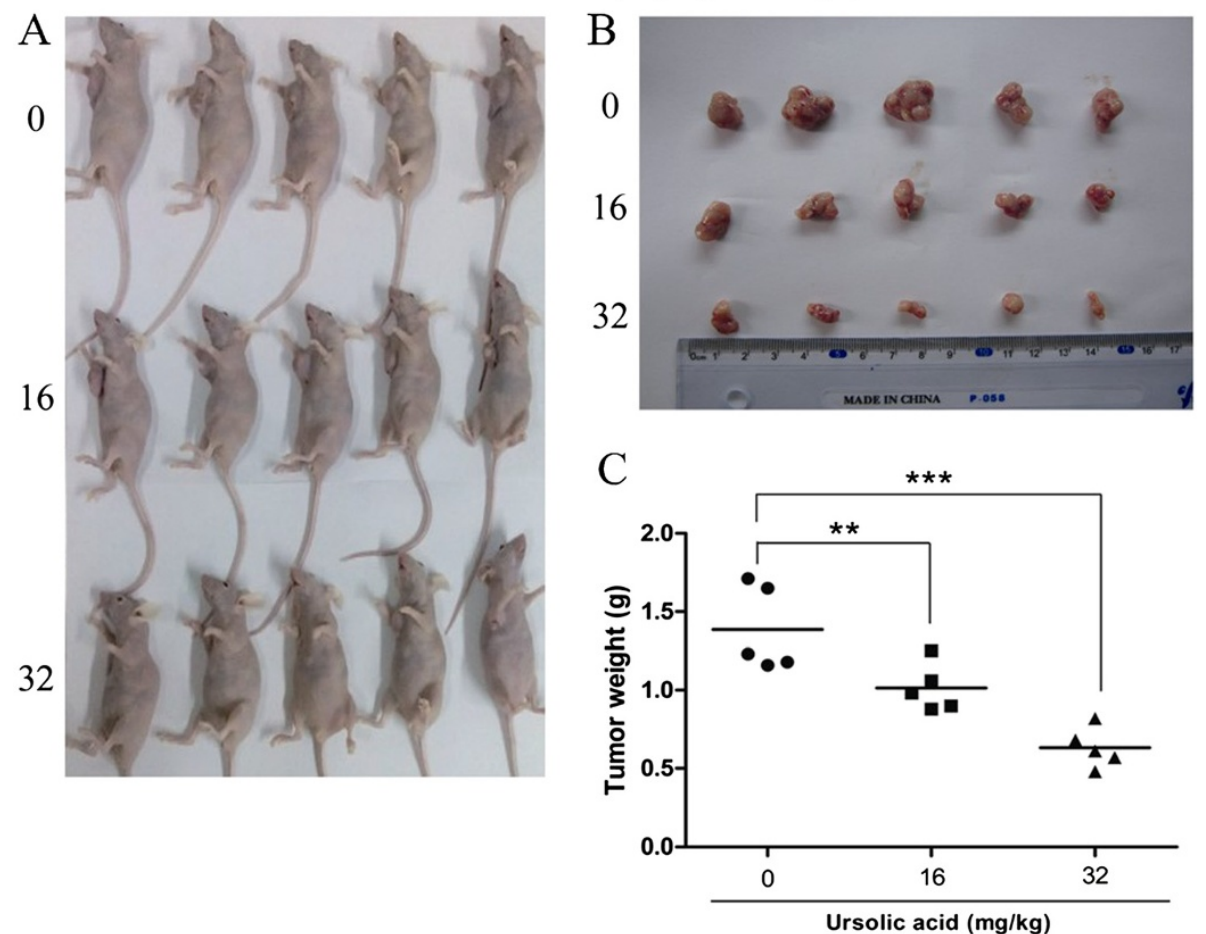

Figure 6 UA suppressed the growth of tumor in nude mice injected with GBC-SD cells. (A) GBC-SD cells were subcutaneously injected into the right flank of the nude mice; The mice were then administered $0.2 \mathrm{~mL}$ of vehicle (10\% DMSO and 90\% PBS) or UA (16 mg/kg and $32 \mathrm{mg} / \mathrm{kg}$ ) intraperitoneally everyday for up to 22 days. Photos of 5 representative mice $(n=10)$ from each group were presented to show the sizes of the resulting tumors; $(\mathbf{B}, \mathbf{C})$ Tumors were excised from the animals and weighed. ${ }^{*} \mathrm{P}<0.05{ }^{*} \mathrm{P}<0.01$ vs. the control group.

was removed, and fresh medium containing various concentrations of UA $(0,40,50,60$ or $70 \mu \mathrm{mol} / \mathrm{L})$ were added. The cells were further cultured for 24,48 or $72 \mathrm{~h}$. Then, $40 \mu \mathrm{L}$ of $5 \mathrm{mg} / \mathrm{mL}$ MTT in PBS was added to each well and incubated for another $4 \mathrm{~h}$. Next, $100 \mathrm{~mL}$ of DMSO was used to dissolve the formazan crystals that formed. Cell proliferation was evaluated by measuring the optical density (OD) at $490 \mathrm{~nm}$ using an Automated Microplate Reader (Bio-Tek, USA). The percentage of viable cells was calculated using the following formula: cell viability $(\%)=$ $(\mathrm{OD}$ of treated cells/OD of control cells $) \times 100$. All experiments were repeated three times.

\section{Colony formation assay}

GBC-SD and SGC-996 cells in the logarithmic growth phase were digested using trypsin-EDTA (Gibco, USA) solution and then seeded in 6-well culture plates at a density of 500 and 600 cells/well, respectively. After adherence, the cells were treated with UA $(0,8,16$ or $32 \mu \mathrm{mol} / \mathrm{L}$ ) for $48 \mathrm{~h}$, then cultured for 15 days. The cells were then fixed with methanol and stained with a $5 \%$ Giemsa solution, and colonies ( $>50$ cells) were counted under an inverted microscope. The reported results represent the average of 3 independent experiments performed over multiple days.

\section{Cell cycle analysis}

GBC-SD and SGC-996 cells were seeded in 6-well plates at $1.5 \times 10^{5}$ cells/well and treated with UA $(0,40,50,60$ or $70 \mu \mathrm{mol} / \mathrm{L}$ ) for $48 \mathrm{~h}$. Then, the cells were collected, fixed with cold $70 \%$ ethanol and stored at $-20^{\circ} \mathrm{C}$. After thawing and centrifugation, the cells were washed with cold PBS, re-suspended and fixed in $70 \%$ ice-cold ethanol for $4 \mathrm{~h}$ at $4^{\circ} \mathrm{C}$, then incubated at $37^{\circ} \mathrm{C}$ for $30 \mathrm{~min}$ with $10 \mathrm{mg} / \mathrm{mL}$ RNase. Finally, $1 \mathrm{mg} / \mathrm{mL}$ propidium iodide (Sigma-Aldrich) was used to stain the cells. DNA content analysis was performed using flow cytometry (San Diego, $\mathrm{BD}, \mathrm{USA})$. The percentage of cells present in the different cell cycle phases was determined using Cell Quest acquisition software (BD Biosciences).

\section{Flow cytometric analysis of cell apoptosis}

Cell apoptosis levels were measured with an Annexin V-FITC apoptosis detection kit (BD Biosciences, USA) in accordance with the manufacturer's instructions. In brief, GBC-SD and SGC-996 cells $\left(10^{5}\right.$ cells $/ 2 \mathrm{~mL} /$ well $)$ 
were seeded in 6-well plates and incubated with different concentration of UA $(0,40,50,60$ or $70 \mu \mathrm{mol} / \mathrm{L})$ for $36 \mathrm{~h}$. The cells were then collected, resuspended in $100 \mu \mathrm{L}$ of $1 \times$ binding buffer containing $2.5 \mu \mathrm{L}$ of FITC-conjugated annexin-V and $1 \mu \mathrm{L}$ of PI $(100 \mu \mathrm{g} / \mathrm{mL})$ and incubated for another 15 minutes in the dark. The results were then analyzed using flow cytometry (San Diego, BD, USA).

\section{Detection of variation in the mitochondrial membrane potential $(\Delta \Psi \mathrm{m})$}

$\Delta \Psi \mathrm{m}$ was analyzed by flow cytometry using Rhodamine 123 staining. After treatment with UA $(0,40,50,60$ or $70 \mu \mathrm{mol} / \mathrm{L}$ ) for $48 \mathrm{~h}$, the culture medium was removed, and cells were washed twice with PBS. The cells were then incubated in Rhodamine 123 staining solution $(5 \mu \mathrm{g} / \mathrm{mL})$ for $25 \mathrm{~min}$ at $37^{\circ} \mathrm{C}$. The samples were analyzed using a flow cytometer (BD, Biosciences, USA).

\section{Western blotting analysis}

GBC-SD and SGC-996 cells $\left(1 \times 10^{7}\right)$ were seeded in a cell culture dish and treated with different concentrations of UA for $48 \mathrm{~h}$. A BCA assay (Shanghai, Beyotime, China) was used to determine cell protein concentrations after harvesting the treated cells and extracting proteins using RIPA buffer according to the method described by Levites et al. [25]. For western blot analysis, equal quantities $(50 \mu \mathrm{g}$ of protein per lane) of total proteins mixed with bromophenol blue $(0.01 \%)$ were added in each lane and separated by SDS-PAGE, then electrophoretically transferred onto PVDF membranes. The membrane was blocked in blocking buffer (5\% non-fat dry milk) for $1 \mathrm{~h}$ at room temperature, then incubated with anti-cleaved caspase-3, anti-cleaved caspase-9, anti-PARP, anti-Bcl-2, anti-Bax, anti-cytochrome c, and anti- $\beta$-actin antibodies in blocking buffer at $4{ }^{\circ} \mathrm{C}$ overnight. This was followed by an incubation with a goat anti-rabbit/anti-mouse secondary antibody conjugated with horseradish peroxidase (1:5000; Abcam). After each incubation period, the membranes were washed three times with TBS/T. The immunoreactive bands were visualized using a chemiluminescent HRP substrate (ECL; GE Healthcare), then scanned and quantified with a Gel Doc 2000 (BioRad, USA). The results are representative of 3 independent experiments.

\section{In vivo efficacy of UA}

Six- to eight-week-old mail athymic nude mice were purchased from Shanghai SLAC Laboratory Animal Co., Ltd. (Shanghai, China). They were maintained in a pathogenfree environment. All experimental procedures were preformed strictly follow the international ethical guidelines and the National Institutes of Health Guide concerning the Care and Use of Laboratory Animals and were approved by the institutional guidelines of Shanghai Jiaotong
University (Shanghai, China). To establish a tumor xenograft model, $2 \times 10^{6}$ GBC-SD cells in log-phase growth were suspended in $0.1 \mathrm{ml}$ serum-free culture medium and subcutaneously injected into the left axilla of all nude mice. After 24 hours, 45 mice were randomly divided into 3 groups (15 mice/group). Mice in the first group were treated with vehicle solvent (10\% DMSO and 90\% PBS) intraperitoneally. UA in a dose of $16 \mathrm{mg} / \mathrm{kg}$ and $32 \mathrm{mg} / \mathrm{kg}$ was intraperitoneally injected into the mice of other two groups everyday. On day 22, all mice were sacrificed, the tumor was harvested and weighed. 5 mice in each group were randomly chose to be shown in the figure.

\section{Statistical analysis}

Each experimental value was expressed as the mean \pm standard deviation (SD). All statistical analyses were performed using SPSS16.0 software. The differences between groups were assessed by Student's t-test and were considered significant when the $\mathrm{p}$ value was less than 0.05 . Statistical significance is denoted as follows: ${ }^{*} \mathrm{p}<0.05$, *** $\mathrm{p}<0.01$, and $* * \mathrm{p}<0.001$. All data points represent the mean of triplicate data points.

\section{Competing interests}

The authors have declared that there is no competing interest.

\section{Authors' contributions}

WH and TZJ were responsible for the experiments design, data analysis, and paper writing. HYP, SYJ, BRF and JL participated in experiments execution. WXS, LML, DQ and WXA helped in data statistics. XSS, LHF and CY checked the data correctness and revised the manuscript. LYB and TF were responsible for the supervision and management of the project. All authors have contributed to and approved the final manuscript.

\section{Acknowledgements}

This study was supported by National Natural Science Foundation of China (No. 81172026, 81272402,81301816 and 81172029), National High Technology Research and Development Program (863 Program) (No. 2012AA022606), Foundation for Interdisciplinary research of Shanghai Jiao Tong University (No. YG2011ZD07), Shanghai science and technology commission inter-governmental international cooperation project (No. 12410705900), Shanghai science and technology commission medicalguiding project (No.12401905800), Program for Changjiang Scholars, Natural Science Research Fundation of Shanghai Jiao Tong University School of Medicine (No. 13XJ10037), Leading Talent program of Shanghai and Specialized Research Fundation for Ph.D Program of Higher EducationPriority Development Field (No. 20130073130014 ).

\section{Author details}

'Department of General Surgery, Xinhua Hospital, Affiliated to Shanghai Jiao Tong University, School of Medicine, Shanghai, China. ${ }^{2}$ Laboratory of General Surgery, Xinhua Hospital, Affiliated to Shanghai Jiao Tong University, School of Medicine, Shanghai, China. ${ }^{3}$ Institute of Biliary Tract Disease, Shanghai Jiao Tong University School of Medicine, No. 1665 Kongjiang Road, Shanghai 200092, China. ${ }^{4}$ Gastrointestinal Surgery, Shaoxing People's Hospital Shaoxing Hospital of Zhejiang University, No. 568 Zhongxing North Road, Shaoxing 312000, Zhejiang Province, China.

Received: 23 April 2014 Accepted: 10 September 2014

Published online: 29 October 2014

\section{References}

1. Miller G, Jarnagin WR: Gallbladder carcinoma. Eur J Surg Oncol 2008, 34(3):306-312. 
2. Tan Z, Li M, Wu W, Zhang L, Ding Q, Wu X, Mu J, Liu Y: NLK is a key regulator of proliferation and migration in gallbladder carcinoma cells. Mol Cell Biochem 2012, 369(1-2):27-33.

3. Rifatbegovic Z, Mesic D, Ljuca F, Zildzic M, Morankic M: Incidence and surgical treatment of cancer in gallbladder. Med Arh 2007, 61(1):30-33.

4. Wang J, Liu L, Qiu H, Zhang X, Guo W, Chen W, Tian Y, Fu L, Shi D, Cheng J, Huang W, Deng W: Ursolic acid simultaneously targets multiple signaling pathways to suppress proliferation and induce apoptosis in colon cancer cells. PLOS ONE 2013, 8(5):e63872.

5. Wang JS, Ren TN, Xi T: Ursolic acid induces apoptosis by suppressing the expression of FoxM1 in MCF-7 human breast cancer cells. Med Oncol 2012, 29(1):10-15.

6. Liu XS, Jiang J: Induction of apoptosis and regulation of the MAPK pathway by ursolic acid in human leukemia K562 cells. Planta Med 2007 73(11):1192-1194.

7. Manu KA, Kuttan G: Ursolic acid induces apoptosis by activating p53 and caspase-3 gene expressions and suppressing NF-kappaB mediated activation of bcl-2 in B16F-10 melanoma cells. Int Immunopharmacol 2008, 8(7):974-981.

8. Shanmugam MK, Ong TH, Kumar AP, Lun CK, Ho PC, Wong PT, Hui KM, Sethi G: Ursolic acid inhibits the initiation, progression of prostate cancer and prolongs the survival of TRAMP mice by modulating pro-inflammatory pathways. PLoS ONE 2012, 7(3):e32476.

9. Pathak AK, Bhutani M, Nair AS, Ahn KS, Chakraborty A, Kadara H, Guha S, Sethi G, Aggarwal BB: Ursolic acid inhibits STAT3 activation pathway leading to suppression of proliferation and chemosensitization of human multiple myeloma cells. Mol Cancer Res 2007, 5(9):943-955.

10. Tang C, Lu YH, Xie JH, Wang F, Zou JN, Yang JS, Xing YY, Xi T: Downregulation of survivin and activation of caspase- 3 through the $\mathrm{PI} 3 \mathrm{~K} /$ Akt pathway in ursolic acid-induced HepG2 cell apoptosis. Anticancer Drugs 2009, 20(4):249-258.

11. Checker R, Sandur SK, Sharma D, Patwardhan RS, Jayakumar S, Kohli V, Sethi G, Aggarwal BB, Sainis KB: Potent anti-inflammatory activity of ursolic acid, a triterpenoid antioxidant, is mediated through suppression of NF-kappaB, AP-1 and NF-AT. PLoS ONE 2012, 7(2):e31318.

12. $X u$ WR, Lin HS, Chen $X Y$, Zhang $Y$ : Yin-yang balance therapy on regulating cancer stem cells. J Tradit Chin Med 2011, 31(2):158-160.

13. Jiang M, Huang O, Zhang X, Xie Z, Shen A, Liu H, Geng M, Shen K. Curcumin induces cell death and restores tamoxifen sensitivity in the antiestrogen-resistant breast cancer cell lines MCF-7/LCC2 and MCF-7/LCC9. Molecules 2013, 18(1):701-720.

14. Zhang Z, Wang X, Wu W, Wang J, Wang Y, Wu X, Fei X, Li S, Zhang J, Dong $P, G u$ J, Liu Y: Effects of matrine on proliferation and apoptosis in gallbladder carcinoma cells (GBC-SD). Phytother Res 2012, 26(6):932-937.

15. Liu Z, Li D, Yu L, Niu F: Gallic acid as a cancer-selective agent induces apoptosis in pancreatic cancer cells. Chemotherapy 2012, 58(3):185-194.

16. Eom SH, Gu GJ, Suh CW, Koh KO, Kim DY, Eom YB, Youn HS: Suppression of inducible nitric oxide synthase expression induced by Toll-like receptor agonists by (E)-1-(2-(2-nitrovinyl)phenyl)pyrrolidine. Int Immunopharmacol 2013, 17(2):205-209.

17. Dong P, Zhang Y, Gu J, Wu W, Li M, Yang J, Zhang L, Lu J, Mu J, Chen L, Li S, Wang J, Liu Y: Wogonin, an active ingredient of Chinese herb medicine Scutellaria baicalensis, inhibits the mobility and invasion of human gallbladder carcinoma GBC-SD cells by inducing the expression of maspin. J Ethnopharmacol 2011, 137(3):1373-1380

18. Tan Z, Zhang S, Li M, Wu X, Weng H, Ding Q, Cao Y, Bao R, Shu Y, Mu J, Dong Q, Wu W, Yang J, Zhang L, Liu Y: Regulation of cell proliferation and migration in gallbladder cancer by zinc finger X-chromosomal protein. Gene 2013, 528(2):261-266

19. Liu TY, Tan ZJ, Jiang L, Gu JF, Wu XS, Cao Y, Li ML, Wu KJ, Liu YB: Curcumin induces apoptosis in gallbladder carcinoma cell line GBC-SD cells. Cancer Cell Int 2013, 13(1):64.

20. Earnshaw WC, Martins LM, Kaufmann SH: Mammalian caspases: structure, activation, substrates, and functions during apoptosis. Annu Rev Biochem 1999, 68:383-424.

21. Lee HJ, Auh OS, Lee YM, Kang SK, Chang SW, Lee DS, Kim YC, Kim EC: Growth inhibition and apoptosis-inducing effects of cudraflavone $B$ in human oral cancer cells via MAPK, NF-kappaB, and SIRT1 signaling pathway. Planta Med 2013, 79(14):1298-1306.

22. Antonsson B, Martinou JC: The Bcl-2 protein family. Exp Cell Res 2000 256(1):50-57.
23. Danial NN: BCL-2 family proteins: critical checkpoints of apoptotic cell death. Clin Cancer Res 2007, 13(24):7254-7263.

24. Lavrik IN, Golks A, Krammer PH: Caspases: pharmacological manipulation of cell death. J Clin Invest 2005, 115(10):2665-2672.

25. Levites Y, Youdim MB, Maor G, Mandel S: Attenuation of 6hydroxydopamine (6-OHDA)-induced nuclear factor-kappaB (NF-kappaB) activation and cell death by tea extracts in neuronal cultures. Biochem Pharmacol 2002, 63(1):21-29.

doi:10.1186/s12935-014-0096-6

Cite this article as: Weng et al:: Ursolic acid induces cell cycle arrest and apoptosis of gallbladder carcinoma cells. Cancer Cell International

2014 14:96

\section{Submit your next manuscript to BioMed Central and take full advantage of:}

- Convenient online submission

- Thorough peer review

- No space constraints or color figure charges

- Immediate publication on acceptance

- Inclusion in PubMed, CAS, Scopus and Google Scholar

- Research which is freely available for redistribution 